\title{
FDG PET/CT in follow UP patients with colorectal carcinoma after adjuvant chemotherapy
}

\author{
Remon Zaher Elia, Rafik Abdelazem Elbastawessy * (1), Hanaa Abdelkader Abdelmgeguid and \\ Ahmed Mohamed Bassiouny
}

\begin{abstract}
Background: 18F-2-fluoro-2-deoxy-D-glucose (18F-FDG) positron emission tomography-computed tomography (PET-CT) is a method of imaging that assesses and measures metabolic avidity in cancer cells, acting as a proxy for underlying cellular activity and vitality and so providing anatomic and metabolic information. 18F-FDG PET-CT is beneficial for detecting local recurrence, distant metastases, and monitoring tumor viability after chemotherapy and radiotherapy in patients with colorectal cancer. Strict adherence to set protocols, technological processes, and good patient preparation are essential to produce the greatest results. The goal of the trial was to see how useful PET/CT was in following up on patients who had resected colorectal cancer and had completed adjuvant chemotherapy rounds.
\end{abstract}

Results: In this study, PET/CT early detected hepatic deposits, pulmonary masses, bone deposits, and sizable LNs. PET/CT provided useful information and had a considerable impact on disease management, enabling the detection of recurrent disease as early as possible with high accuracy in assessment of therapeutic response. It detected viable residual tumor cells in operative bed scar, small metabolically active LNs, hepatic focal lesions, peritoneal deposits, pulmonary secondaries, and bone deposits avoiding unnecessary surgeries.

Conclusion: Because of its high accuracy in detection and capacity to identify recurrent illness, FDG-PET-CT imaging is effective in evaluating post-therapeutic colorectal cancer patients with suspected tumor recurrence or distant metastases.

Keywords: FDG PET/CT, Colorectal carcinoma, Adjuvant chemotherapy

\section{Background}

Colorectal cancer (CRC) is the third most prevalent malignant tumor in both men and women in the developed world, as well as the second leading cause of cancerrelated mortality [1].

Despite breakthroughs in surgical treatment and the introduction of combination therapeutical modalities, 5 -year survival rates seldom reach $60 \%$, ranging from $90 \%$ in localised illness to $11 \%$ in patients with distant

${ }^{*}$ Correspondence: rafikbek78@gmail.com

Ain Shams University Faculty of Medicine, Cairo, Egypt organ metastasis. Because of the high risk of recurrence or metachronous metastasis in patients with colorectal cancer, non-invasive restaging and therapeutic monitoring are becoming increasingly popular. Patients' prognosis have been shown to improve when recurrences are detected early [2].

A non-invasive technique to restaging for suspected locally recurring colorectal cancer, detecting probable metastatic disease, and assessing therapy efficacy is becoming increasingly important. CT and MRI have become standard in such examinations, while PET and PET/CT have been proved to be highly successful for 
Table 1 Demographic data of the studied patients

\begin{tabular}{ll}
\hline & Total no. $=\mathbf{3 0}$ \\
\hline Age & \\
Mean $\pm S D$ & $58.03 \pm 12.34$ \\
Range & $36-77$ \\
Gender & \\
Female & $20(66.7 \%)$ \\
Male & $10(33.3 \%)$ \\
\hline
\end{tabular}

specific uses in this population over the last two decades [3].

18 F-fluorodeoxy glucose positron emission tomography/computed tomography (FDG-PET/CT) can detect tumor changes caused by chemotherapy and targeted therapy earlier than CT and better than other imaging modalities like contrast-enhanced multidetector computed tomography (MDCT) and magnetic resonance imaging (MRI) in distinguishing benign post-treatment changes from local recurrence and detecting undetected metastases [4].

Many studies have investigated the use of 18 F-FDG $\mathrm{PET} / \mathrm{CT}$ in the evaluation of therapy response in colorectal cancer, with the goal of treatment individualization to get the best possible therapeutic outcome [5].

In comparison to anatomical changes, the biological effect of therapy, as seen on PET/CT imaging, was thought to be a greater predictive indicator [6].

The goal of this study is to evaluate the role of PET/CT in follow up patients with resected colorectal carcinoma and finished cycles of adjuvant chemotherapy.
Table 2 Pathological results and treatment of the studied patients

Total no. $=30$

\begin{tabular}{lr}
\hline Pathology & \\
Adenocarcinoma & $26(86.7 \%)$ \\
Mucinous & $4(13.3 \%)$ \\
Treatment & \\
Surgery & \\
No & $0(0.0 \%)$ \\
Yes & $30(100.0 \%)$ \\
Chemo/radio & \\
Chemo & $24(80.0 \%)$ \\
Combined & $6(20.0 \%)$ \\
\hline
\end{tabular}

\section{Methods}

This is a prospective study was carried out at Egyptian Military and Ain Shams University Hospitals within a period of 24 months. The study includes 30 patients who are histopathologically confirmed colorectal carcinoma, curative resection of the primary tumor and on follow up after finishing adjuvant chemotherapy.

The inclusion criteria of the study were no age predilection and both genders. While patients with previous history of another type of malignancy, strong history of atopic disorders and renal function impairment (with serum creatinine $>2 \mathrm{mg} / \mathrm{dl}$ ) were excluded from the study.

Ethical permission was obtained from the radiodiagnosis and nuclear medicine committee of Ain Shams University and Military hospitals. The study group was informed about the nature and the purpose of the study. Confidentiality was ensured.

Table 3 Relation of gender of the studied patients with PET-CT findings in follow up patients with colorectal carcinoma after adjuvant chemotherapy

\begin{tabular}{|c|c|c|c|c|c|c|}
\hline & & $\begin{array}{l}\text { Female } \\
\text { No. }=\mathbf{2 0}\end{array}$ & $\begin{array}{l}\text { Male } \\
\text { No. }=10\end{array}$ & Test value & $P$-value & Sig. \\
\hline Recurrence & Positive & $15(75.0 \%)$ & $3(30.0 \%)$ & $5.625^{*}$ & 0.018 & S \\
\hline Local spread & Positive & $15(75.0 \%)$ & $3(30.0 \%)$ & $5.625^{*}$ & 0.018 & S \\
\hline Metastases & Positive & $10(50.0 \%)$ & 7 (70.0\%) & $1.086^{*}$ & 0.297 & NS \\
\hline Hepatic deposits & Positive & $6(30.0 \%)$ & $6(60.0 \%)$ & $2.500^{*}$ & 0.114 & NS \\
\hline Pulmonary deposits & Positive & $4(20.0 \%)$ & $4(40.0 \%)$ & $1.364^{*}$ & 0.243 & NS \\
\hline Local LNs & Positive & $16(80.0 \%)$ & $2(20.0 \%)$ & $10.000^{*}$ & 0.002 & $\mathrm{HS}$ \\
\hline Distant LNs & Positive & $8(40.0 \%)$ & $3(30.0 \%)$ & $0.287^{*}$ & 0.592 & NS \\
\hline Bone deposits & Positive & $3(15.0 \%)$ & $3(30.0 \%)$ & $0.938^{*}$ & 0.333 & NS \\
\hline Peritoneal deposits & Positive & $4(20.0 \%)$ & $0(0.0 \%)$ & $2.308^{*}$ & 0.129 & NS \\
\hline False + ve & Positive & $2(10.0 \%)$ & $1(10.0 \%)$ & $0.000^{*}$ & 1.000 & NS \\
\hline False -ve & Positive & $2(10.0 \%)$ & $1(10.0 \%)$ & $0.000^{*}$ & 1.000 & NS \\
\hline
\end{tabular}

*Chi-square test 
Table 4 Relation of pathological results of the studied patients with PET-CT findings in follow up patients with colorectal carcinoma after adjuvant chemotherapy

\begin{tabular}{|c|c|c|c|c|}
\hline & $\begin{array}{l}\text { Pathology } \\
\text { Adenocarcinoma } \\
\text { No. }=26\end{array}$ & $\begin{array}{l}\text { Test value } \\
\text { Mucinous } \\
\text { No. }=4\end{array}$ & $P$-value & Sig. \\
\hline Recurrence & Positive & $\begin{array}{l}0.192^{*} \\
16(61.5 \%)\end{array}$ & $\begin{array}{l}0.661 \\
2(50.0 \%)\end{array}$ & NS \\
\hline Local spread & Positive & $\begin{array}{l}0.192^{*} \\
16(61.5 \%)\end{array}$ & $\begin{array}{l}0.661 \\
2(50.0 \%)\end{array}$ & NS \\
\hline Metastases & Positive & $\begin{array}{l}6.036^{*} \\
17(65.4 \%)\end{array}$ & $\begin{array}{l}0.014 \\
0(0.0 \%)\end{array}$ & S \\
\hline Hepatic deposits & Positive & $\begin{array}{l}3.077^{*} \\
12(46.2 \%)\end{array}$ & $\begin{array}{l}0.079 \\
0(0.0 \%)\end{array}$ & NS \\
\hline Pulmonary deposits & Positive & $\begin{array}{l}1.678^{*} \\
8(30.8 \%)\end{array}$ & $\begin{array}{l}0.195 \\
0(0.0 \%)\end{array}$ & NS \\
\hline Local LNs & Positive & $\begin{array}{l}0.192^{*} \\
16(61.5 \%)\end{array}$ & $\begin{array}{l}0.661 \\
2(50.0 \%)\end{array}$ & NS \\
\hline Distant LNs & Positive & $\begin{array}{l}2.672^{*} \\
11(42.3 \%)\end{array}$ & $\begin{array}{l}0.102 \\
0(0.0 \%)\end{array}$ & NS \\
\hline Bone deposits & Positive & $\begin{array}{l}1.154^{*} \\
6(23.1 \%)\end{array}$ & $\begin{array}{l}0.283 \\
0(0.0 \%)\end{array}$ & NS \\
\hline Peritoneal deposits & Positive & $\begin{array}{l}0.710^{*} \\
4(15.4 \%)\end{array}$ & $\begin{array}{l}0.399 \\
0(0.0 \%)\end{array}$ & NS \\
\hline False + ve & Positive & $\begin{array}{l}0.513^{*} \\
3(11.5 \%)\end{array}$ & $\begin{array}{l}0.474 \\
0(0.0 \%)\end{array}$ & NS \\
\hline False-ve & Positive & $\begin{array}{l}21.667^{*} \\
0(0.0 \%)\end{array}$ & $\begin{array}{l}0.000 \\
3(75.0 \%)\end{array}$ & $\mathrm{HS}$ \\
\hline
\end{tabular}

${ }^{*}$ Chi-square test

All included patients were subjected to full history taking with emphasis on the clinical data of the patients, routine laboratory investigations, the 18 F-FDG PET/ CT examinations were performed on colorectal cancer patients during their follow up period after finishing adjuvant chemotherapy, and before FDG administration, all patients had a blood glucose level of less than $200 \mathrm{mg} /$ dL (11.1 mmol/L).

\section{Study procedures}

296-444 MBq of FDG was administered intravenously 50-60 min before undergoing PET and CT scanning.
Table 5 Relation of treatment of the studied patients with PET-CT findings in follow up patients with colorectal carcinoma after adjuvant chemotherapy

\begin{tabular}{|c|c|c|c|c|}
\hline & $\begin{array}{l}\text { Chemo/radio } \\
\text { Chemo } \\
\text { No. }=24\end{array}$ & $\begin{array}{l}\text { Test value } \\
\text { Combined } \\
\text { No. }=6\end{array}$ & $P$-value & Sig. \\
\hline Recurrence & Positive & $\begin{array}{l}0.139^{*} \\
14(58.3 \%)\end{array}$ & $\begin{array}{l}0.709 \\
4(66.7 \%)\end{array}$ & NS \\
\hline Local spread & Positive & $\begin{array}{l}0.139^{*} \\
14(58.3 \%)\end{array}$ & $\begin{array}{l}0.709 \\
4(66.7 \%)\end{array}$ & NS \\
\hline Metastases & Positive & $\begin{array}{l}1.663^{*} \\
15(62.5 \%)\end{array}$ & $\begin{array}{l}0.197 \\
2(33.3 \%)\end{array}$ & NS \\
\hline Hepatic deposits & Positive & $\begin{array}{l}0.139 * \\
10(41.7 \%)\end{array}$ & $\begin{array}{l}0.709 \\
2(33.3 \%)\end{array}$ & NS \\
\hline Pulmonary deposits & Positive & $\begin{array}{l}0.384^{*} \\
7(29.2 \%)\end{array}$ & $\begin{array}{l}0.536 \\
1(16.7 \%)\end{array}$ & NS \\
\hline Local LNs & Positive & $\begin{array}{l}0.313^{*} \\
15(62.5 \%)\end{array}$ & $\begin{array}{l}0.576 \\
3(50.0 \%)\end{array}$ & NS \\
\hline Distant LNs & Positive & $\begin{array}{l}1.292^{*} \\
10(41.7 \%)\end{array}$ & $\begin{array}{l}0.256 \\
1(16.7 \%)\end{array}$ & NS \\
\hline Bone deposits & Positive & $\begin{array}{l}0.052^{*} \\
5(20.8 \%)\end{array}$ & $\begin{array}{l}0.819 \\
1(16.7 \%)\end{array}$ & NS \\
\hline Peritoneal deposits & Positive & $\begin{array}{l}1.154^{*} \\
4(16.7 \%)\end{array}$ & $\begin{array}{l}0.283 \\
0(0.0 \%)\end{array}$ & NS \\
\hline False + ve & Positive & $\begin{array}{l}4.537^{*} \\
1(4.2 \%)\end{array}$ & $\begin{array}{l}0.033 \\
2(33.3 \%)\end{array}$ & S \\
\hline False -ve & Positive & $\begin{array}{l}0.833^{*} \\
3(12.5 \%)\end{array}$ & $\begin{array}{l}0.361 \\
0(0.0 \%)\end{array}$ & NS \\
\hline
\end{tabular}

*Chi-square test

PET emission images for $5-7$ bed positions were collected using a weight-based technique with $3 \mathrm{~min}$ of acquisition time per bed position. Three hours later, a delayed imaging of the ROI or suspected lesion location was performed. CT, PET, and combined PET/CT transverse, sagittal, and coronal sections were produced with a section thickness of $5 \mathrm{~mm}$ using an iterative technique and CT-based attenuation correction. In order to interpret the images, visual assessment and semi-quantitative analysis were used. The highest standardised uptake value (SUVmax $=$ SUVmax, delayed-SUVmax, early) was retrieved at the area that most clearly showed the hyperintensive radioactivity. 


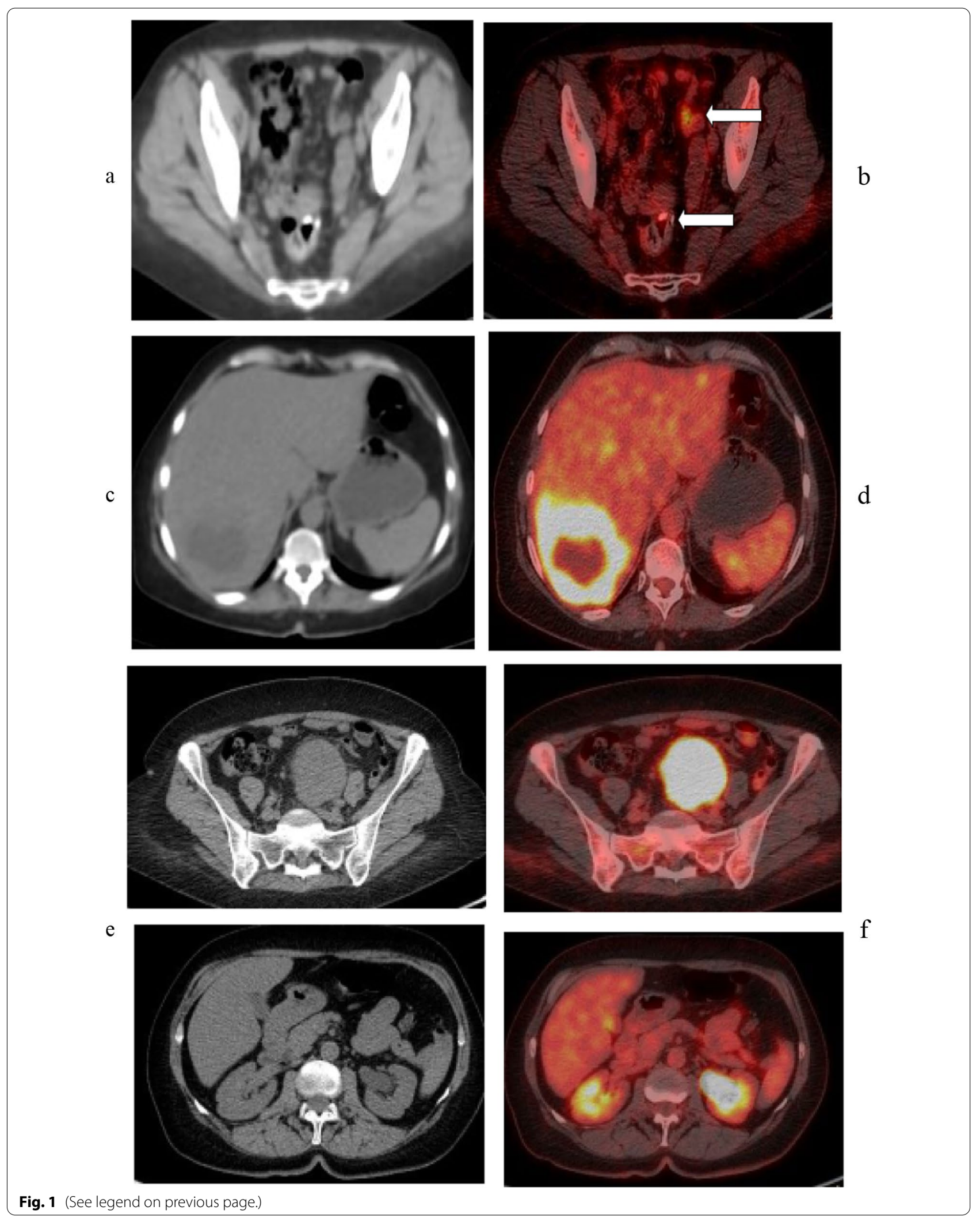




\section{Statistical analysis}

Data were collected, revised, coded and entered to the Statistical Package for Social Science (IBM SPSS) version 20 and the following were done: Quantitative data was provided as mean, standard deviations, and ranges, whereas quantitative data were presented as mean, standard deviations and ranges. The comparison between two groups with qualitative data were done by using $X^{2}$ test. The confidence interval was set at $95 \%$, while the acceptable margin of error was set at $5 \%$.

\section{Results}

This prospective study was conducted in Egyptian Military and Ain Shams University Hospitals on 30 patients with age ranged from 36 to 77 years with mean \pm SD of $58.03 \pm 12.34$; they were 20 females $(66.7 \%)$ and 10 males (33.3\%) (Tables 1, 2, 3).

The previous table shows that there was statistically significant increase in the percentage of recurrence, local spread and local lymph nodes in females than males with $p$-value $=0.018,0.018$ and 0.002 respectively while no statistically significant relation found between gender of the studied patients and the other findings (Table 4).

The previous table shows that there was statistically significant increase in the percentage of patients with metastases in adenocarcinoma group than mucinous group with $p$-value $=0.014$; also the table shows that there was statistically significant increase in the false negative rate in mucinous group than adenocarcinoma group with $p$-value $<0.001$ while no statistically significant relation found between pathological results and the other findings (Table 5).

The previous table shows that there was statistically significant increase in the false positive rate in patients with combined treatment than those with chemotherapy only with $p$-value $=0.033$ while no statistically significant relation found between treatment of the studied patients and the other findings.

\section{Sample of study cases}

Figures 1, 2 and 3.

\section{Discussion}

Colorectal cancer is the third leading cause of cancer worldwide, accounting for a substantial number of tumor-related deaths. Recurrence occurs in roughly onethird of patients during the first two years after surgery.

Due to its direct examination of malignant cellular metabolism, PET/CT has been shown to have a crucial role in early diagnosis of post-therapeutic recurrence in patients with cancer colon.

It plays an important role in detecting metabolically active small LNs, local operative bed recurrence, small metastasis, early osseous deposits, and post-therapeutic evaluation of viable and non-viable malignant lesions (post chemotherapy and radiotherapy).

This study was conducted on 30 patients with age ranged from 36 to 77 years old with mean $\pm S D$ of $58.03 \pm 12.34$; they were 20 females $(66.7 \%)$ and 10 males (33.3\%).

Based on lesions analysis, the final diagnosis of local recurrence/spread in post-therapeutic cancer colon was visible in 18 cases (60.0 percent) of the patient group.

The study almost agreed with Mittal et al. [7], who found recurrences in 71 percent of post-operative CRC patients using PET/CT, but these findings differ from those of Hetta et al. [8] analyzed 60 instances and discovered that 22 cases (36.7 percent of the total evaluated cases) developed a local recurrence and 38 cases did not (63.3 percent percentage of the total studied cases). The study looked at the sensitivity, specificity, and accuracy of PET/CT in detecting local recurrence in colorectal cancer patients who had completed their treatment. The accuracy is 96.7 percent, with a sensitivity of 95.45 percent, a specificity of 97.36 percent, and a sensitivity of 95.45 percent.

In this study, the number of patients with local nodal involvement were 18 cases $(60 \%)$. While 12 patients did not develop nodal metastatic deposits (40\%).

The findings are consistent with those of O'Connor et al. [9], who found that on PET-CT, enlarged and nonenlarged FDG avid lymph nodes can be seen in the mesentery, indicating the existence of regional lymph node metastases; this is shown when patients with CRC are restaged. The study agreed because the research found

(See figure on next page.)

Fig. 2 a NCCT axial image at the level of rectal surgical interference showed surgical clips with no abnormality detected, b Fused PET- CT confirmed and revealed no FDG-active lesions denoting no residue or local recurrence. c CECT mediastinal window showed subcarinal as well as right hilar enlarged lymph nodes, $\mathbf{d}$ Fused PET-CT axial image confirmed and revealed hypermetabolic active lymph nodes (SUVmax measures 17.9). e NCCT showed right basal pulmonary $+4 \mathrm{~cm}$ soft tissue density mass lesion. f Fused PET- CT axial image confirmed and revealed right basal pulmonary hypermetabolic active deposit (SUVmax reaches 15). $\mathbf{g}$ NCCT axial image revealed C2 osteolytic lesion with extra osseus soft tissue component, $\mathbf{h}$ Fused PET-CT image confirmed FDG-overactive lesion destructing the anterior neural arch of C2 (SUVmax measures 10) as well as avid right deep cervical LN. i NCCT serial axial bone window images showed osteolytic lesions at the spinous process of L2 vertebra as well as right iliac bone, $\mathbf{j}$ Fused PET-CT images confirmed and revealed overactive bony deposits (SUVmax measures 10 \& 16 respectively) 


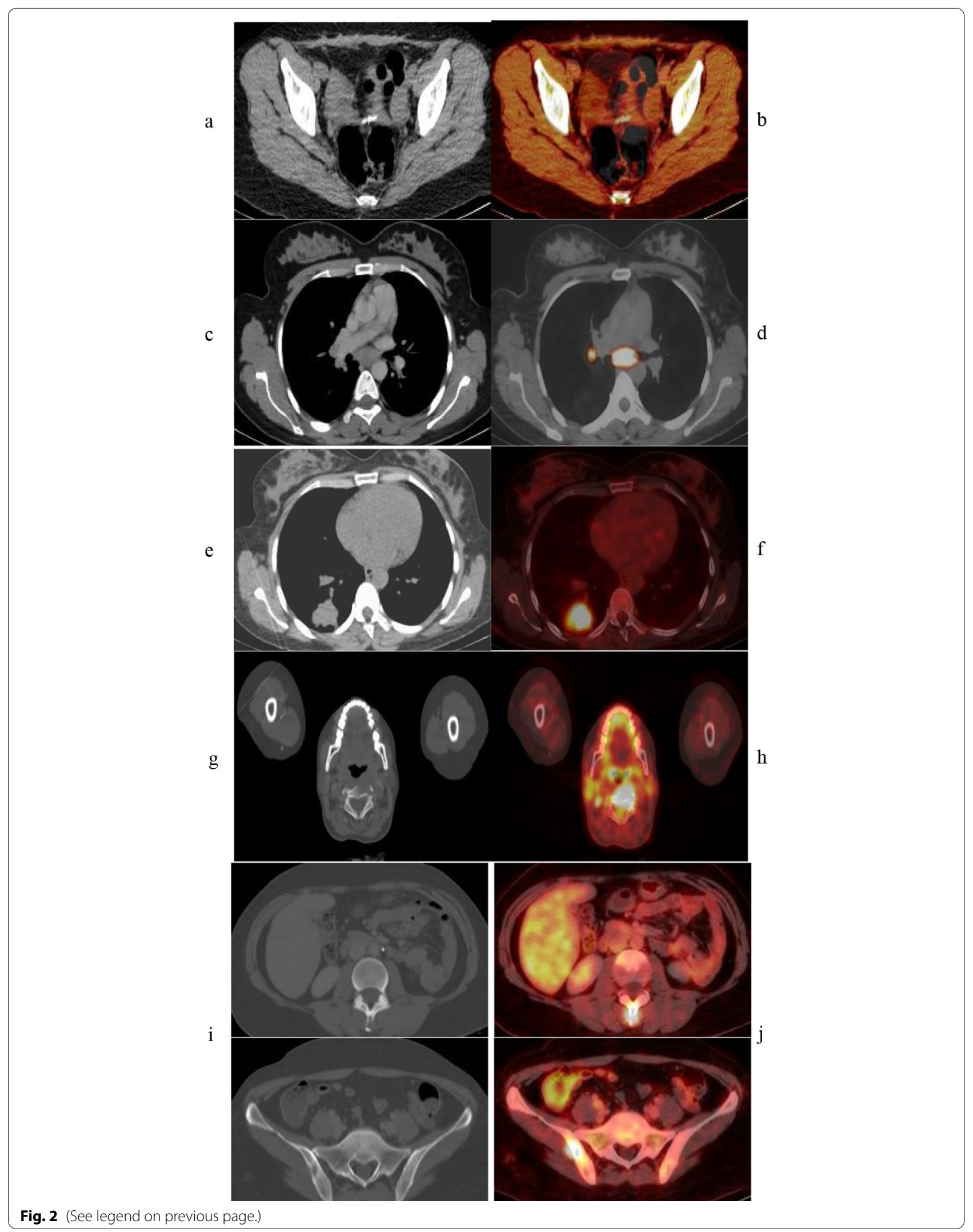


that $\mathrm{PET} / \mathrm{CT}$ was quite sensitive in detecting regional lymph nodes; however, this contradicts Kim et al. [10], who found that nodal 18F-FDG uptake findings were highly specific for LN metastatic status, but had a low sensitivity; this study's low sensitivity was attributed to the fact that the subsequent study excluded patients who had received neoadjuvant treatment, and they stated that if these advanced rectal cancer patients who had received neoadjuvant chemotherapy were included in the current study, the LN detectability of 18F-FDG PET/CT would be improved because the majority of these patients had shown high nodal 18F-FDG uptake.

The end diagnosis of distant metastases in posttherapeutic cancer colon was visible in 17 individuals (56.7\%) of the patient group based on lesions investigation. Patients with hepatic metastatic deposits accounted for 12 instances (40\%); those with pulmonary nodular deposits accounted for 8 cases $(26.7 \%)$; those with osseous deposits accounted for 6 cases (20\%); and those with peritoneal deposits accounted for four cases (40\%).

PET/CT was therefore useful in detecting hepatic and extrahepatic metastases.

The findings are consistent with those of Kijima et al. [11], who found that FDG-PET and PET/CT have high accuracy for the detection and staging of liver lesions in CRC patients, with a combined sensitivity and specificity of 93 percent, and Zhang et al. [12], who found that PET/CT had better sensitivity and specificity $(87-100$ percent and 90-98 percent, respectively) for the detection and staging of liver lesions in CRC patients.

In this study, females had a statistically significant higher rate of PET-CT detection of recurrence, local spread, and local lymph nodes than males, with p-values of $0.018,0.018$, and 0.002 , respectively, whereas there was no statistically significant relation between gender of the studied patients and the other findings, which could be due to small sample size.

In this study There was statistically significant increase in the PET-CT false negative rate in mucinous group than adenocarcinoma group with $p$-value $<0.001$ while no statistically significant relation found between pathological results and the other findings.

The findings were consistent with those of Whiteford et al. [13] and Borasio et al. [14], who found that mucinous adenocarcinoma was responsible for two-quarters of false-negative cases and that mucinous carcinoma was the most common cause of false-negative scans. They stated that mucinous colorectal carcinoma has lower uptakes on FDG-PET imaging than non-mucinous carcinoma and that FDG-PET sensitivity for mucinous adenocarcinoma is much lower than non-mucinous carcinomas, which is completely consistent with the findings. PET/CT was also unable to identify vitality in sub centimetric hepatic focal lesions and pulmonary nodules, as well as the evaluation of mucinous tumor deposits, particularly in hypocellular lesions with extensive mucin, according to Lee et al. [15]. The use of a delayed regional scan has recently been found to be more effective in detecting these metastases.

In investigation, patients who had combined treatment had a statistically significant higher false positive rate than those who received only chemotherapy ( $p$-value $=0.033)$, but no statistically significant relation was established between the treatment of the investigated patients and the other findings.

The findings are consistent with those of Hetta et al. [8], who found that there were 60 patients in all, with 21 true positive cases, 37 true negative cases, one false-positive case, and one false-negative case. The false-positive case had positive long segment enhancing rectal mural thickening around the anastomotic site with high FDG uptake (high SUVmax), but it was later proven to be a negative case (colitis) after the second biopsy; the follow-up examination, done 6 months later with no treatment or further management, shows regressive course regarding the mural thickening and metabolic act. The false-negative case had low SUV-max at the collapsed rectosigmoid colon site and presacral soft tissue sheet; the known falsenegative results of colorectal mucinous adenocarcinoma

\footnotetext{
(See figure on next page.)

Fig. 3 a NCCT of the abdomen showing soft tissue density related to the operative bed inseparable from the left ilio-psoas muscle complex. $\mathbf{b}$ Fused PET-CT image revealed and confirmed operative bed FDG avid metabolically overactivity denoting recurrence, infiltrating the left ilio-psoas muscle (SUVmax measures 13). c NCCT of the abdomen showing thickened left peri-renal fascia. d Fused PET-CT image confirmed FDG avid metabolic overactivity (SUVmax measures 10). The arrow refers to left ureteric double-J catheter. e NCCT of the abdomen showing nodular soft tissue density at the left anterior abdominal wall (arrow). f Fused PET-CT image confirmed FDG avid metabolic overactivity (arrow) (SUVmax measures 9). $\mathbf{g}$ NCCT of the abdomen showing right hepatic lobe segment-IV ill-defined hypodense focal lesion $\pm 3.5 \mathrm{~cm}$ in diameter, $\mathbf{h}$ Fused PET-CT image confirmed right hepatic lobe segment-IV FDG avid hypermetabolic active focal lesion eliciting (SUVmax 12.5). i NCCT Iung window axial image shows right para hilar speculated soft tissue density mass lesion $\pm 3 \mathrm{~cm}$ surrounded by reticular densities and atelectatic bands (arrow) j Fused PET -CT image confirmed right para-hilar FDG avid hypermetabolic active deposit (SUVmax measures 16.5) (arrow). k NCCT lung window axial image shows small peripheral nodule $(+7 \mathrm{~mm}$ ) at the right lower lung lobe (arrow), I Fused PET-CT image revealed FDG-avid small nodule of low grade activity at the left upper lung lobe (SUVmax measures 2.7) (arrow)
} 


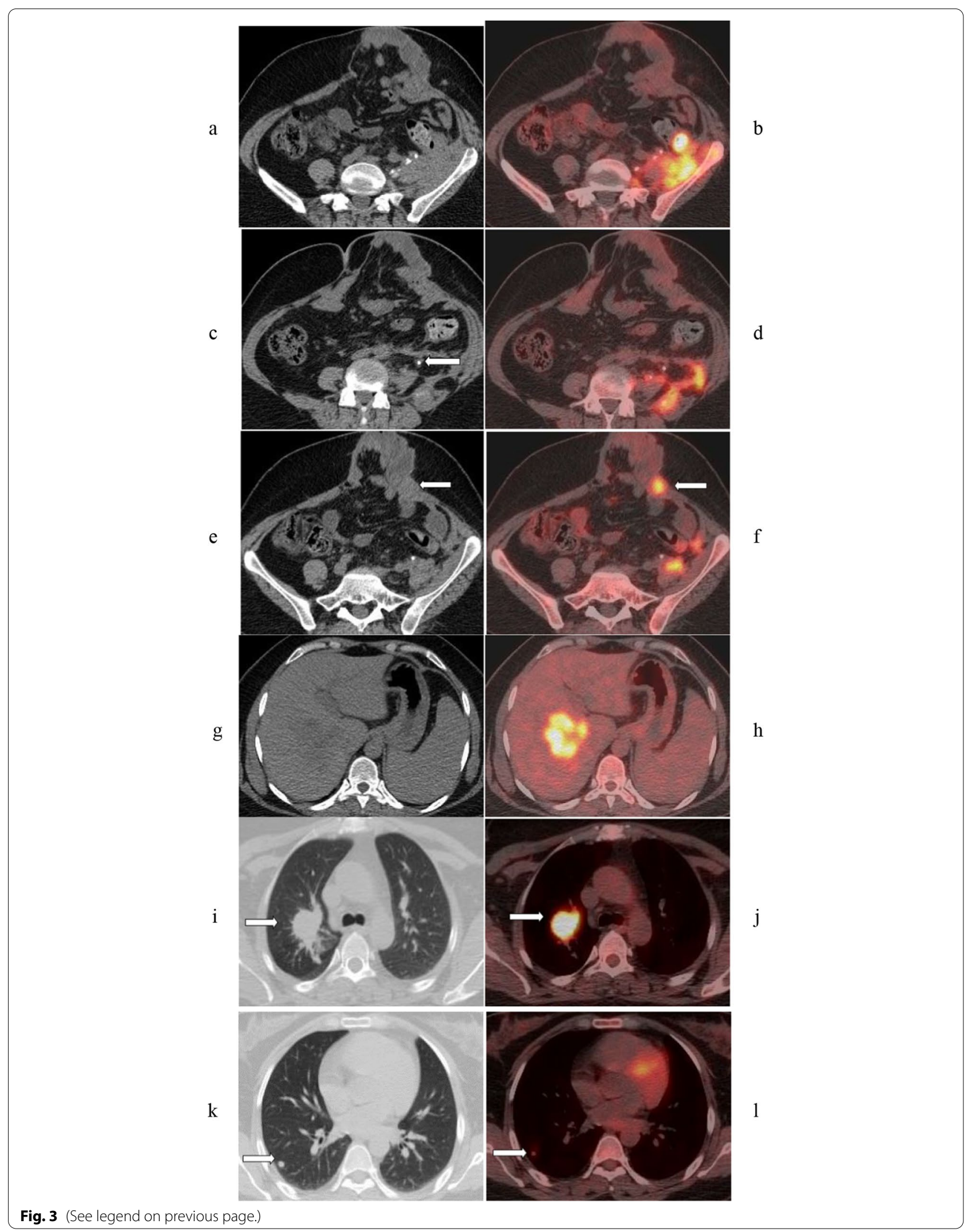


were concerning for a biopsy, which revealed positive tumor recurrence, and follow-up studies after chemotherapy showed uptake and size regression.

In investigation, the percentage of PET-CT metastases detected in the adenocarcinoma group was statistically significantly higher than in the mucinous group (65.4 percent, $p$-value $=0.014$ ).

These findings matched those of Mittal et al. [7], who studied 73 patients ( 55 males, 18 females; age range 25 to 80 years) with histopathologically established CRC who received FDG PET/CT imaging for the identification of recurrence and/or metastasis after initial treatment. In 51 patients, rising CEA levels were found. PET/CT scans were positive in 13 patients ( 3 with liver lesions, 5 with lymph node involvement, 2 with bone metastases, 1 with local recurrence in the urinary bladder wall, 1 with lymph node and liver metastases, and 1 with lymph node and bone metastases), resulting in a change in management.

Going along with the findings of Chen et al. [16], who comprised 56 and 158 patients with a history of colorectal cancer who came with increasing CEA levels and conventional imaging modalities suggested an ambiguous reason for the elevated CEA level. PET/CT had a sensitivity of 98.1 percent and a specificity of 75 percent.

Chiewvit et al. [17] have shown that 18F-FDG PET/ $\mathrm{CT}$ is a viable approach in postoperative evaluation of patients with suspected recurring colorectal malignant lesions and a normal CEA level, as previously reported and corroborated by the investigation. Local recurrences or metastases can be distinguished from postoperative alterations or benign disease features by 18F-FDG PET/ CT.

As previously mentioned, PET/CT has been demonstrated to be useful in detecting post-therapeutic cancer colon recurrence and distant metastasis. PET/CT scans revealed greater information and better lesion characterization.

\section{Conclusion}

Because of its high accuracy in detection and capacity to identify recurrent disease, FDG-PET-CT imaging is effective in evaluating post-therapeutic colorectal cancer patients with suspected tumor recurrence or distant metastases.

\footnotetext{
Abbreviations

18F-FDG: 18F-2-fluoro-2-deoxy-D-glucose; CRC: Colorectal cancer; FDG-PET/ $\mathrm{CT}$ : $18 \mathrm{~F}$-fluorodeoxy glucose positron emission tomography/computed tomography; MDCT: Multidetector computed tomography; PET-CT: Positron emission tomography-computed tomography; ROI: Region of interest; SPSS: Statistical package for social science.
}

\section{Acknowledgements}

None.

\section{Authors' contributions}

All authors of this research paper have directly participated in the planning, execution, or analysis of this study. All authors of this paper have read and approved the final version submitted. The contents of this manuscript have not been copyrighted or published previously; The contents of this manuscript are not now under consideration for publication elsewhere; The contents of this manuscript will not be copyrighted, submitted, or published elsewhere, while acceptance by the Journal is under consideration.

\section{Funding}

None.

\section{Availability of data and materials}

Availability of data and materials: The datasets used and/or analyzed during the current study are available from the corresponding author on reasonable request.

\section{Declarations}

Ethics approval and consent to participate

This study was approved by the Faculty of Medicine Ain Shams University, Research Ethics Committee. Each patient was provided a written informed consent for analysis of anonymized data.

\section{Consent for publication}

All patients included in this research gave written informed consent to publish the data contained within this study. Patients who where less than 16-yearold, deceased, or unconscious when consent for publication was requested, written informed consent for the publication of this data was given by their parents or legal guardians.

\section{Competing interests}

The authors declare that they have no competing interests.

Received: 23 August 2021 Accepted: 9 November 2021

Published online: 29 November 2021

\section{References}

1. Mant D, Gray A, Pugh S et al (2017) A randomized controlled trial to assess the cost-effectiveness of intensive versus no scheduled follow-up in patients who have undergone resection for colorectal cancer with curative intent. Health Technol Assess 21(32):1-86

2. National Cancer Institute. Surveillance, epidemiology, and end results program. Cancer stat facts: colon and rectum cancer. Accessed 10 July 2017

3. Patel K, Hadar N, Lee J, Siegel BA, Hillner BE, Lau J (2017) The lack of evidence for PET or PET/CT surveillance of patients with treated lymphoma, colorectal cancer, and head and neck cancer: a systematic review. J Nucl Med 4-6

4. Skougaard K, Nielsen D, Vittrup BJ, Pfeiffer P, Hendel HW (2016) Early 18F-FDG-PET/CT as a predictive marker for treatment response and survival in patients with metastatic colorectal cancer treated with irinotecan and cetuximab. Acta Oncol 55:9-10

5. Grassetto G, Capirci C, Marzola MC et al (2012) Colorectal cancer: prognostic role of F-18-FDG-PET/CT. Abdom Imaging 37:575-579

6. Wahl RL, Jacene H, Kasamon Y, Lodge MA (2009) Evolving considerations for PET response criteria in solid tumors. J Nucl Med 50:122S-S150

7. Mittal BR, Senthil R, Kashyap R, Bhattacharya A, Singh B, Kapoor R, Gupta $R$ (2011) 18F-FDG PET-CT in evaluation of postoperative colorectal cancer patients with rising CEA level. Nucl Med Commun 32(9):789-793

8. Hetta W, Niazi G, Abdelbary MH (2020) Accuracy of 18F-FDG PET/CT in monitoring therapeutic response and detection of loco-regional recurrence and metastatic deposits of colorectal cancer in comparison to CT. Egypt J Radiol Nucl Med 51(1):1-8

9. O'Connor OJ, Mc dermott S, Slattery J, Sahani D, Blake MA (2011) The use of PET-CT in the assessment of patients with colorectal carcinoma. Int J Surg Oncol 846512 
10. Kim SH, Song B-I, Kim BW, Kim HW, Won KS, Bae SU, Jeong WK, Baek SK (2019) Predictive value of [18F]FDG PET/CT for lymph node metastasis in rectal cancer. Sci Rep 9:4979

11. Kijima S, Sasaki T, Nagata K, Utano K, Lefor AT, Sugimoto H (2017) Preoperative evaluation of colorectal cancer using CT colonography, MRI, and PET/CT. World J Gastroenterol 20(45):16964

12. Zhang Y, Feng B, Zhang G-L, Hu M, Zheng F, Zhao F, Zhang X-L, Kong L, Jin-Ming Y (2014) Value of 18F-FDG PET-CT in surveillance of postoperative colorectal cancer patients with various carcinoembryonic antigen concentrations. World J Gastroenterol 20(21):2219-2840

13. Whiteford MH, Whiteford HM, Yee LF, Ogunbiyi OA, Dehdashti F, Siegel BA, Birnbaum EH, Fleshman JW, Kodner IJ, Read TE (2010) Usefulness of FDG-PET scan in the assessment of suspected metastatic or recurrent adenocarcinoma of the colon and rectum. Dis Colon Rectum 43(6):759-767

14. Borasio P, Gisabella M, Billé A, Righi L, Longo M, Tampellini M, Ardissone F (2011) Role of surgical resection in colorectal lung metastases: analysis of 137 patients. Int J Colorectal Dis 26:183-190

15. Lee JW, Kim SK, Lee SM, Moon SH, Kim TS (2011) Detection of hepatic metastases using dual-time-point FDG PET/CT scans in patients with colorectal cancer. Mol Imag Biol 13(3):565-572

16. Chen LB, Tong JL, Song HZ, Zhu H, Wang YC (2007) 18F-DG PET/CT in detection of recurrence and metastasis of colorectal cancer. World J Gastroenterol 13(37):5025

17. Chiewvit $S$, Jiranantanakorn $T$, Apisarnthanarak P, Kanchaanapiboon $P$, Hannanthawiwat C, Ubolnuch K, Phongsawat N, Chiewvit P (2013) Detection of recurrent colorectal cancer by 18F-FDG PET/CT comparison with contrast enhanced CT scan. J Med Assoc Thai 96(6):703-708

\section{Publisher's Note}

Springer Nature remains neutral with regard to jurisdictional claims in published maps and institutional affiliations.

\section{Submit your manuscript to a SpringerOpen ${ }^{\circ}$ journal and benefit from:}

- Convenient online submission

- Rigorous peer review

- Open access: articles freely available online

- High visibility within the field

- Retaining the copyright to your article

Submit your next manuscript at $\boldsymbol{\nabla}$ springeropen.com 